\title{
Characterization of the Four-Stage Structure of the Process of Learning Motor Actions in Sports Games
}

\author{
Naumchuk Volodymyr Ivanovych \\ Department of Theoretical Foundations and Methods of Physical Education, Ternopil Volodymyr Hnatiuk National Pedagogical \\ University, Ukraine
}

Received October 28, 2019; Revised November 15, 2019; Accepted November 22, 2019

Copyright $(2019$ by authors, all rights reserved. Authors agree that this article remains permanently open access under the terms of the Creative Commons Attribution License 4.0 International License

\begin{abstract}
The purpose of this review is to summarize the views of researchers on the structure of the process of learning motor actions in sports games and justify the feasibility of its four-stage construction. The structure of motion learning is an open pedagogical system which reflects its most general patterns by revealing the typical interrelations among the elements of the stages of learning. Each preliminary stage of learning in motor actions provides a logical basis for the next, and its planned intermediate result corresponds to a certain functional formation, which gradually transforms into another, thus causing a transition to a higher level. The expediency of a four-stage structure of the process of learning motor actions in sports games is conditioned by a set factors, such as: establishing a link between the content of each of the stages of learning and the corresponding functional formation; ensuring the focus of learning on the transition from a method of reproducing motor actions to a fundamentally different - creative problem solving; creation of necessary conditions for the integration of motor actions in game and competitive activity; the use of the pedagogical potential of the game itself in the process of motor actions learning; ensuring a clear sequence and continuity of the pedagogical process; resolving the contradiction between the automation of motor actions and the role of consciousness in the cognitive process.
\end{abstract}

Keywords Learning, Structure, Motor Action, Sports Games

\section{Introduction}

\subsection{The Scientific and Practical Relevance of Sports Games}

Sports games are an integral part of humanity's holistic culture and are being integrated as a whole in integration with its other components. In today's world, gaming is represented by a wide variety of players. Due to their attractiveness and accessibility, they are one of the common and favorite types of exercise in people of different social groups, regardless of their age, gender, profession or place of residence. Complex and multidimensional nature, multifunctionality, ability to cover various manifestations of the human psyche and activity provide a constant scientific and practical relevance for the sports games.

In the scientific and educational space, sports games are considered as a universal factor of comprehensive and harmonious development of the individual, and their value is determined by the possibility of active and simultaneous influence on the psychophysiological and motor spheres of the person [1-4]. The pedagogical possibilities of games are connected with the spiritual-moral and physical perfection of the individual, forming of their humanistic and value orientations. The further search for ways to realize the potential of sports games in different parts of the education system necessitates their comprehensive knowledge as an effective tool for pedagogical influence.

\subsection{Learning of Motor Actions as a Pedagogical Process}

Learning of motor actions is a continuous pedagogical process of sensually rational cognition and practical mastery of the technique of physical exercises. It aims to assimilate the human with rational and effective ways of managing their movements, acquiring in this way the appropriate skills and related knowledge [5-8]. Mastery of various motor actions should ensure not only the formation and development of the ability of a person to control movements, but also the study of the patterns of movement of their body [9]. This purposeful process involves the long-term storage of information through exercise or 
repetition of motor tasks [10]. The other side of the holistic pedagogical process is education, which implies the formation of values, moral norms as a component of physical culture and sport and impossible without the process of education.

Like any other, the process of learning how to move is formed by closely related components: target, incentive and motivational, content, operational and effective, control regulating, evaluative and effective. An indisputable fact, which confirms the correctness of training, is the ability of a person to retain motor skills and apply them in different conditions through automation, since practical (game) situations in real life are usually accidental [11]. Important factors in the development of motor skills and their performance are the structure and features of the environment, cognitive, physical and emotional characteristics of the individual, information about perception and specific tasks [12].

To solve the problem of holistic motor training, a conditional division of this long process into several successive stages is carried out. Joint actions of all subjects of learning initially involve the creation of an idea of movement, the formation of a basic model of coordination $[13,14]$. After that, in the motor actions purposefully eliminates the initial discrepancy and lack of coordination, replaced by template and precise movements [15]. Due to the increase of smoothness and relaxation of the basic and elimination of unnecessary movements, the quality of performance of motor actions is gradually improved $[14,16]$. Subsequently, the kinematic and dynamic parameters of the movements are integrated, causing their automation $[4,17]$.

The process of teaching game techniques must transform the static representation of motor activity into dynamic research. Such transformation requires the discovery of the driving forces that form it, the establishment of the dynamic qualities of all components of this pedagogical process, the relationship among them, and therefore the refinement of structure. In this context, the purpose of this review is to summarize the views of researchers on the structure of the process of learning motor actions in sports games and justify the feasibility of its four-stage construction.

\section{Research Methods}

To achieve this goal, a set of interrelated methods was used, namely: analysis of scientific approaches to the structure of the process of teaching motor actions, synthesis, summarization and comparison of scientific information on the problem of research, educational literature and Internet sources.

\section{Results and Discussion}

\subsection{The Theoretical Basis of the Process of Learning Motor Actions in Sports Games}

In sports games, the process of teaching game techniques is aimed, first of all, at mastering the technique - such ways of performing motor actions, with the help of which motor tasks are solved with the greatest efficiency and allow to gain an advantage over the opponent [3]. In this case, the proper solution of the motor problem is possible only if the purposeful formation of the propulsion system and the movement system. The student must understand the role and importance of each of the motor actions in the game and competitive activities, know the necessary conditions for their formation and improvement [2].

The results of training in game techniques are associated with certain functional entities, which are defined primarily as motor ability and skills. In the process of learning how to move, the nature of motion control changes, which causes an increase in mastering the technique of sports games. Therefore, the formation of motor skills is always preceded by the development of the student's motor ability.

Motor ability is equated with such a level of mastery of game action, which is characterized by conscious movement management, instability to the action of factors that hinder its performance and instability of results $[4,6]$. Its essence is the continuous improvement of the way of performing the action in a meaningful approach in the process of motor control. The development of motor ability requires the active participation of the learning subject, awareness and analysis of the tasks assigned to them, the conditions of their fulfillment, management of their own intellectual and motor activity.

In turn, motor skill is considered as the optimum level of mastery of the technique of action, which is characterized by automated (with minimal control of consciousness) motor control, high stability and reliability of execution $[8,9]$. With automated motor control, consciousness is freed from the necessary control over the details of movements, which, on the one hand, facilitates the functioning of higher mechanisms of motor control, and on the other, allows you to focus attention and thinking on the result and conditions of action. As Kostyukevych [1, p.68] emphasizes, "mastery of motor skill occurs in accordance with a number of laws: the law of change of speed in the development of skill, the law of "plateau" (delay) in the development of skill, the law of no limit in the development of skill, the law of extinction, the law of transfer of skills, etc." 
According to Fomin and Vavilov [18], in a multi-stage system of arbitrary motors, the skill is nothing more than the acquired ability to solve a particular motor problem. Because the possibilities for improving motor activity are endless, Zheleznyak et al. [3] believe that during purposeful long-term training an athlete can achieve super-skills - a system of higher order skills. This level of mastery of the technique is characterized by variability, creativity, individualization, high stability of performance of integral motor actions in game and competitive conditions in the presence of adverse factors of internal and external environment. Super-skills arise on the basis of reliable motor skills of performance of separate game techniques, high level of development of physical qualities and system of special knowledge. Unlike motor skills, super-skills are characterized by an increase in the role of consciousness, which provides analysis of information in various game situations, conducted in conditions of limitation of time, making the right decision, choosing the appropriate reception of the game and its method, timely and quality execution.

The process of teaching motor action is largely determined by the fact that it combines the pedagogical, psychological and physiological laws of the formation of motor skills with the laws of management theory and the requirements of the principles of didactics and sports training. However, in sports, as noted by Platonov [19, p.279], "it is the pedagogical setting for the execution of the movement that is the most important element that enables the athlete to exert motor action in all the complex interaction of rationally planned mechanical, biological and psychological components".

According to Bernstein [20], psychophysiological mechanisms of motor construction are manifested at different levels - spinal and medulla, subcortical centers and cortex. Each level, as a layer in the central nervous system, has specific motor manifestations. As a rule, there are several levels involved in the organization of movements - directly the one on which the movement is built and all others below. However, in the human consciousness are represented only those components of the movement, which are built at a higher, leading level, and the work of the lower levels is largely unaware. In Bernstein's [20] views, the main meaning of the notion of the system of motors lies in the integrity and interconnectedness of the individual motors, which transform them into a monolithic formation. The level of construction of any movement is determined by its content or task, which emphasizes the crucial importance of such a psychological and pedagogical category as the goal (motor task) for the organization and course of physiological processes.

General mechanisms for the control of arbitrary motors are presented in the theory of functional systems of Anokhin [21]. The latter are considered by the researcher as a dynamic self-regulating organization, the activity of all components of which contributes to obtaining vital adaptive results for the body. According to Anokhin [21], the central system-forming factor for each functional system is the result of activity. Functional system is a universal model for understanding and building any structure, including motor action. Thus, any complete movement consists of different phases that are consistently changing, namely: afferent synthesis, decision making, acceptor of results of action, efferent synthesis, formation of action and evaluation of the achieved result [21].

Developed by Halperin [22], the theory of the stepwise formation of action proves the determining role of consciousness in the formation and subsequent application of motor actions. Accordingly, when learning any action, it is advisable to distinguish between two parts: orientation and execution. The indicative basis of action includes a system of conditions, factors, and basic anchor points elements of motor action that require concentration of attention for its successful implementation. The main task of forming a motor action is to form its orientation part, because it determines performance. Therefore, according to the recommendations of Bohen [23], the efforts of the subjects of training should be directed not at the formulation of movements, that is, the creation and development of the executive part of the motor actions, but at the formation of their orientation basis.

In general, the structure of the process of learning movement actions can be understood as the internal construction of the pedagogical process of learning and mastering the technique of sports games, the integrity and identity of which is ensured by a set of legitimate relationships of all components [19]. In constructing the learning process, it is customary to distinguish among certain stages, which pedagogical science considers relatively in isolation. The definition of stages is a conditional distribution of the process of learning motor action, which reflects the pedagogical and psychophysiological patterns. Since ability is a pedagogical category and a skill is psychophysiological, as Ashmarin [5, p.97] points out, "all the levels of ownership of a motor action can be expressed by the words: "I know", "I know well", "I know perfectly". Each stage has its own peculiarities and is characterized by the peculiarity of the cognitive activity of the students, their ability to control their movements while performing the game play being studied.

\subsection{Substantiation of Expediency of a Four-Stage Structure of the Process of Learning Motor Actions in Sports Games}

Today, there are differing views among researchers as to the number of stages of learning movement. Thus, the model of motor skills formation proposed by Gentile [13] provides for two stages of training. The largest group of specialists distinguish three stages $[6-9,19,24,25]$. Some 
scientists, the vast majority of whom are representatives of game sports, identify four stages of training in motor actions [3-5]. Another group of scientists proposes to extend the number of relatively independent stages to five or more $[26,27]$.

The different views of the authors on the number of stages of learning in motor actions can be explained by the specificity of the sport or motor activity, the contingent of subjects of study, the choice of the trajectory of scientific search, its tasks, the characteristics of thinking of specialists, etc. In any case, the structure of motion training cannot be regarded as something permanent and unchanging. It represents only the typical relationships among the elements of the stages, which reflect the most general patterns of learning. At the same time, understanding and realization of the features of each stage allows you to grasp the whole mechanism of learning of motor action, which makes it possible to obtain the planned results.

The difference in the number of stages means the difference in their orientation and content, and, accordingly, a certain imbalance of tasks, means, methods and pedagogical conditions of the holistic process of formation of motor actions. In order to substantiate the optimal number of stages of training in motor actions in sports games, it is advisable to assume that the effectiveness of training at different stages of mastering the game techniques is ensured, including establishing a relationship between the content of each of them and the corresponding functional creation. At the same time, the goal of each stage should be oriented and directly reflect the result - the formation of functional entities that act as intermediate achievements in the path of sports and technical improvement. And if in the theory and practice of sports games they distinguish four functional entities - motor imagination, motor ability, skills and higher order skills system (super-skills), then it would be logical to determine a similar number of stages of training in motor actions.

Given the specificity of sports games, it is necessary to note a few more factors that determine the primacy of the four-stage structure. Thus, the need for the proper solution of motor problems in a constantly changing environment requires the continuous development of the athlete's ability to creativity, improvise, and creative use of the system of motor actions. After all, the indispensable component of the implementation of any sport game is individual knowledge. In this process, which always occurs on the basis of high activity of the participants of the game, it is possible to distinguish the following defining types of activities: a) activities for assimilation and application of ready information or motor skills in familiar situations; $b$ ) the activity, the meaning of which is to identify possible modifications of the action of already learned patterns, to diversify and combine motor actions in changing conditions; c) activities aimed at self-discovery of patterns, improvement and integration of motor activity.
In game activity, play and creativity mutually penetrate each other, acting in constant unity and interconnection. Reproductive activity, unlike creative, is characterized by the fact that it always ends with the creation of a product on already known patterns or models. In the course of such activity, the student, who is in the conditions of the same type of situations, operates the game techniques of the previously formed system in their own experience. The process of finding the necessary solution to the problem involves replicating existing knowledge and experience, updating and enriching it, as well as the ability to operate them and design new ways of activity. Reproductive actions appear to the creative, on the one hand, as their basis, and on the other - as a derivative of the creative. Creativity derives from reproduction and it is the development of the latter, and contains reproductive processes as one of its derivatives [28]. Starting from the first stage and throughout the process of learning movement, this pattern determines one or another of the leading characteristics of the student's activity, namely: reproductive, reconstructive and variation, partially search-oriented and creative.

The correlation between the processes of reproduction and creativity, as well as the level of manifestation of the latter, as one of the priorities of physical education and sports education, should be reflected in this didactic process and, accordingly, in its structure. Perfect mastery of game techniques (which is the aim of training motor actions) is impossible without the constant creativity of the athlete, the best environment for manifestation of whom is actually the game itself. The ability to take into account the nature of the activity, and in particular, the display of creativity of the player through the direct execution of their motor actions in game and competitive conditions is a valid argument for this.

In addition, training in game techniques should be consistent with the competitive features of sports games that do not allow directional formation of specific types of movement, which significantly depends on the specific game situation, the actions of partners and opponents. In game and competition conditions, no motor action is realized in isolation, and the completion of pre-admission may be the beginning or element of the next. This circumstance significantly increases the importance not only of the wide variability of motor actions, but also of their integration in the game and competitive activities.

Considering the process of training motor actions in game sports in terms of sports training, it is advisable to note the interconnection and engagement of its various parties (components). Actually, the process of sports training is a consistent achievement of the person of the highest possible level of readiness, which largely determines the results of their participation in competitions $[4,8,19]$. The effectiveness of competitive activity in sports games is ensured by an adequate level of all aspects of athletic readiness of each player and team as a whole as a 
result of this long-standing process. However, any aspect of sports training is not an isolated process, because, for example, the technical aspect of solving game tasks is always connected with the intellectual, tactical, physical, and psychological abilities of the athlete. This relationship is determined by the complex nature of the game activity and the integrity of the movement in sports games. Each action of the player arises as a result of the system of knowledge, the manifestation of physical and psychological qualities, motor experience and is realized as a holistic effect, as an integrative formation.

This stipulates the need to take into account the optimal compliance of all parties of sports training in the process of training the motor actions. According to the theory of functional systems developed by Anokhin [21], harmony is achieved not only on the basis of communication and interaction, but is also based on mutual assistance. Accordingly, each side of the athlete's training should be formed and developed in such a combination with the other, in which their mutual assistance will be carried out, so that in our case the level of technical preparedness will positively affect the others. Conversely, by improving the athlete's intellectual, psychological, physical and tactical capabilities, their technical skill will be improved.

In this context, the best means of sports preparation for game and competitive activity, that is, the game itself must be itself. After all, the content of the training process is determined primarily by the content of competitive activities. However, the most commonly used model of playing sports today is not game, but exercise, which significantly impedes the growth of students' sportsmanship $[1,4,29]$. Teaching to play with just one exercise set is a utopia. Physical exercise is a kind of theory of sports games, and game is their practice. The need for systematic work on what the student will deal with on the playground or field during competitions determines the need for optimal use in the training process of the potential of the game itself in its various manifestations. This requires not only the expedient distribution of the means of learning movement by stages, but also the isolation in this purposeful process of another of them - the fourth.

Reflecting on the content and characteristics of the basic assets for each stage of training in motor actions, the structure of this process should also include the conditions for their implementation. The latter are based on the principles of didactics, which determine their relevance to the stages of learning and overall consistency. The optimum vector for the use of motor learning tools is provided by the following conditions: simplified $\rightarrow$ standard $\rightarrow$ variation $\rightarrow$ complicated. At the same time with the change of conditions of exercise realization requirements for quality and efficiency of performance of game receptions increase.

The inclusion of the fourth stage in the structure of learning game techniques reflects the logic of cognition of motor actions. In the three-stage structure of learning, the autonomous stage is the final stage, during which the student learns to perform the game reception without much conscious effort [25,31]. Motor automation is characterized by a diminished role of consciousness in motor control. This fact is confirmed by the results of neurobiological studies, which indicate that the achievement of movement automation requires less activation of the human brain and, accordingly, less attention [30]. The automation of game techniques does not require a conscious concentration of thought on the performance of motor actions, and minimizing the requirements for cognitive processing of information extends the player's ability to process other data. However, the process of cognition, and such in its essence is the training of motor actions, cannot be crowned with a diminishing role of consciousness, the importance of which in gaming is difficult to overestimate. Purposeful attainment of a super-skills that is characterized by an increase in the role of consciousness can be one of the ways to resolve this contradiction.

Therefore, the structure of motor actions learning in game sports should include four steps:

Stage I - creation of preconditions and familiarization with motor actions;

Stage II - mastering motor actions;

Stage III - consolidation and improvement of motor actions;

Stage IV - integration of motor actions (Table 1). 
Table 1. Structure of the Process of Learning Motor Actions in Sports Games

\begin{tabular}{|c|c|c|c|c|}
\hline $\begin{array}{l}\text { Stages of } \\
\text { learning }\end{array}$ & I & II & III & IV \\
\hline Name & $\begin{array}{l}\text { Creation of preconditions } \\
\text { and familiarization with } \\
\text { motor actions }\end{array}$ & Mastering motor actions & $\begin{array}{l}\text { Consolidation and } \\
\text { improvement of motor action }\end{array}$ & $\begin{array}{l}\text { Integration of } \\
\text { motor actions }\end{array}$ \\
\hline Aim & $\begin{array}{c}\text { Mastering of motor } \\
\text { actions in general, in the } \\
\text { basic variant }\end{array}$ & $\begin{array}{l}\text { Detailed, relatively proper } \\
\text { mastering of motor actions }\end{array}$ & $\begin{array}{l}\text { Fixing and improving motor } \\
\text { actions }\end{array}$ & $\begin{array}{l}\text { Integration of motor } \\
\text { actions in game and } \\
\text { competitive activity }\end{array}$ \\
\hline $\begin{array}{l}\text { Nature of } \\
\text { activities }\end{array}$ & Reproductive & Reconstruction and variation & Partial search & Creative \\
\hline Means & $\begin{array}{c}\text { General preparatory and } \\
\text { general developmental } \\
\text { exercise; audiovisual } \\
\text { means }\end{array}$ & $\begin{array}{l}\text { Special preparatory exercise; } \\
\text { audiovisual means; simulators; } \\
\text { moving games }\end{array}$ & $\begin{array}{l}\text { Basic (competitive) exercise; } \\
\text { game tasks; technical training; } \\
\text { moving games }\end{array}$ & $\begin{array}{l}\text { Game tasks; system of } \\
\text { motion, training and } \\
\text { control games }\end{array}$ \\
\hline Conditions & Simplified & Standard & Variable & Complicated \\
\hline Methods & $\begin{array}{l}\text { Verbal; visual; methods of } \\
\text { education of basic and } \\
\text { special physical qualities }\end{array}$ & $\begin{array}{l}\text { Methods of teaching motor } \\
\text { actions in parts and in general; } \\
\text { methods of education of } \\
\text { physical qualities }\end{array}$ & $\begin{array}{l}\text { Methods of teaching motor } \\
\text { actions in general; combined } \\
\text { exposure method; method of } \\
\text { circular training }\end{array}$ & $\begin{array}{l}\text { Combined exposure } \\
\text { method; playing; } \\
\text { competitive }\end{array}$ \\
\hline Result & Motor imagination & Motor ability & Motor skills & $\begin{array}{l}\text { Higher order skills } \\
\text { system (super-skills) }\end{array}$ \\
\hline
\end{tabular}

\subsection{Characteristics of the Stages of Learning Motor Actions in Sports Games}

The purpose of the first stage is to master the students' motor actions in general, in the main version. It is specified through the realization of the following tasks: creating a holistic view of the techniques based on relevant knowledge; determination of students' motor experience and, if necessary, replenishment; ensuring the proper level of development of physical qualities that determine the qualitative mastery of game techniques; implementation of game techniques in general, the formation of an indicative basis of activity; elimination of unnecessary movements that significantly distort the technique. The activities of the students are mainly reproductive in nature. The main means of learning are general preparatory and general development exercises, which are implemented in simplified conditions, as well as audiovisual means. Among the teaching methods most often used are verbal, visual, methods of education of basic and special physical qualities. The result of the first stage of learning the game techniques is a motor imagination.

The detailed, relatively proper mastering of motor activity by students is the purpose of the second stage. Achieving this goal involves solving a set of tasks, namely: refining the technique of game techniques, their spatial, temporal, spatial and temporal and dynamic characteristics regarding the individual abilities of students; deepening understanding of the patterns of movements in the techniques studied; achievement of correct execution of game techniques, increase of students' self-control; creating a prerequisite for the variant implementation of game techniques. Accordingly, the nature of the activity of students from reproductive is transformed into reconstructive and variation. Means of learning are special-preparatory - imitation, showing, developmental exercise, moving games, audiovisual means, simulators and more. Exercise conditions are, for the most part, standard, and the leading ways of interaction between the teacher and the students are the methods of teaching motor actions in parts and in general, the methods of education of physical qualities. At this stage, the formation of motor ability is conducted.

The purpose of the third stage is to consolidate and improve the students' motor actions, and its main tasks are determined such as: consolidation of skills of playing techniques; widening the range of variability of techniques; complete individualization of motor actions. Partial search nature of students' activities mutually determines the use of basic (competitive) exercises, game tasks, moving games, technical training. The learning tools are implemented in variation and changed conditions. The most commonly used at this stage are the methods of motor learning in general, the methods of combined exposure and circle training. The third stage of learning the techniques of the game ends with the formation of motor skills.

The main goal of the fourth stage is the integration of motor activities in the game and competitive activities. The tasks of this stage are associated with the achievement of a complex formation of game techniques and leading physical performance; ensuring high efficiency of implementation of technical techniques in the game. The creative nature of students' activities involves the implementation of learning tools in difficult conditions. Leading tools in the final stage of learning are gaming tasks, a system of motion, training and control games. The main methods are game, competitive and combined influence. During the fourth stage of learning there is the formation 
and development of super-skills - the system of higher order skills.

The solution to the problem of quality learning in game techniques involves a thorough knowledge of the structure of the process of learning motor actions, the corresponding goals, objectives and ways of their implementation. After all, the success of the pedagogical process is determined by the accuracy of the formulation of the goals of learning motor actions, the prediction of the conditions in which it will be carried out, as well as the correctness of the selection and implementation at each stage of tasks, tools, methods necessary to achieve them. This purposeful process requires the active position of the student, their constant intellectual activity, also in agreement with the mastery of the game techniques of the development of motor abilities and personal qualities. It is possible to evaluate the effectiveness of learning by comparing the actual level of mastery of motor actions with the purpose and the specific tasks of the stages of the pedagogical process. In turn, accurate and objectively defined learning outcomes allow you to adjust and supplement the system of goals and objectives, improve the means and methods of pedagogical influence.

\section{Conclusions}

The structure of the process of learning motor actions in sports games represents a complete pedagogical process, which is divided into four stages. The latter include their own specific goals, tasks, tools, and methods that reflect the pedagogical and psychophysiological patterns of formation of motor imagination, motor ability, skills and higher order skills system. Each preliminary stage of learning in motor actions provides a logical basis for the next, and its planned intermediate result corresponds to a certain functional formation, which gradually transforms into another, thereby causing the transition to a higher level.

Among the main factors that determine the feasibility of a four-stage structure of the process of learning motor actions in sports games, such as:

- establishing a link between the content of each of the stages of learning and the corresponding functional formation - motor imagination, motor ability, skills and higher order skills system (super-skills);

- ensuring the focus of learning on the transition from a method of reproducing motor actions to a fundamentally different - creative problem solving;

- creation of necessary conditions for the integration of motor actions in game and competitive activity;

- the use of the pedagogical potential of the game itself in the process of motor actions learning;

- ensuring a clear sequence and continuity of the pedagogical process;
- resolving the contradiction between the automation of motor actions and the role of consciousness in the cognitive process.

In our opinion, this review will help to understand more and realize the process of learning motor actions, fill it with personal meaning, which in practice will improve the quality of motor actions management, and therefore the effectiveness of the pedagogical process.

\section{REFERENCES}

[1] Kostyukevych, V. M. (2014). The theory and methodology of sports training (on the example of team game sports). Vinnytsya: Planer.

[2] Naumchuk, V. I. (2018). Theoretical and methodical bases of teaching sports games. Saarbrücken: LAP LAMBERT Academic Publishing.

[3] Zheleznyak Yu. D., Portnov, Yu. M., Savin, V. P., \& Lexakov, A. V. (2008). Sports games: Technique, tactics, teaching technique. Moscow: Academy.

[4] Zheleznyak Yu. D., Kashkarov, V. A., Chernyh E. V., Kravtsevych, I. P., Panov S. F., Meshcheryakov, I. L., \& Shklyarov, V. B. (2005). Pedagogical physical and sports improvement. Moscow: Academy.

[5] Ashmarin, B. A. (1990). Theory and methodology of physical education. Moscow: Enlightenment.

[6] Kuramshyn, Yu. F. (2010). Theory and Methods of Physical Culture. Moscow: Soviet Sport.

[7] Krutsevich, T. Y. (2003). Theory and methods of physical education. Kyiv: Olympic Literature.

[8] Kholodov, J. K., \& Kuznetsov, V. S. (2000). Theory and methods of physical education and sports. Moscow: Academy.

[9] Shyyan, B. M. (2008). Theory and methods of physical education of students. Ternopil: The Educational Book Bohdan.

[10] Keele, S. J., \& Summers, J. (1976). The structure of motor programs. In G. E. Stelmach (Ed.), Motor control: Issues and trends (pp. 109-141). New York, Academic Press.

[11] Magill, R. A., \& Anderson, D. I. (2014). Motor learning and control: concepts and applications. North Ryde, NSW, McGraw-Hill Education.

[12] Warren, W. (2006). The dynamics of perception and action. Psychological Review, 113 (2), 358-389.

[13] Gentile, A. M. (1972). A working model of skill acquisition with application to teaching. Quest, 17 (1), 3-23. Online available from https://www.tandfonline.com/doi/abs/10.10 $80 / 00336297.1972 .10519717$

[14] Newell, K. M. (1991). Motor skill acquisition. Annual Reviewin Psychology, 42, 213-237. Online available from http://e.guigon.free.fr/rsc/article/Newell91.pdf 
[15] Annett, J. (1985). Motor learning: a review. In H. Heuer, U. K. lewbeck \& K. H. Schmidt (Eds.), Motor behavior: programming, control, and acquisition (189-192) Berlin, Springer-Verlag.

[16] Erkomashvilli, I. V. (2004). Fundamentals of the theory of physical culture. Ekaterinburg.

[17] Cesar, U., Ugrinowitsch, C. H., Benda, R. N., \& Tani, G. (2010). Effects of practice schedule on the adaptive process of motor learning. Rev Port Cien Desp, 10 (1), 158-171. Online available from https://rpcd.fade.up.pt/_arquivo/RP CD_Vol.10_Nr.1.pdf\#page $=40$

[18] Fomin, N. A., \& Vavilov, Yu. N. (1991). Physiological bases of motor activity. Moscow: Physical Education and Sport.

[19] Platonov, V. N. (2015). The system of training athletes in Olympic sports. General theory and its practical applications. Kyiv: Olympic Literature.

[20] Bernstein, N. A. (2012). On the construction of motors. Moscow: Book on Demand.

[21] Anokhin, P. K. (1975). Essays on the physiology of functional systems. Moscow: Medicine.

[22] Halperin, P. Ya., \& Talyzina, N. F. (1968). Formation of knowledge and skills on the basis of the theory of gradual mastering of mental actions. Moscow: Moscow Pub. House. Univ.

[23] Bohen, M. M. (1985). Training in motor actions. Moscow: Physical Education and Sport.

[24] Naskalov, V. M. (2008). Theory and methodology of physical education. Novopolotsk: PSU.

[25] Fitts, P. M., \& Posner, M. I. (1967). Human performance. Belmont, CA: Brooks/Cole Pub. Co.

[26] Schnabel, G. (1987). Motorisches Lernen im Sport. In: K. Meinel \& G. Schnabel. Bewegungslehre - Sportmotorik (172-241). Berlin: Volk und Wissen.

[27] Stark, H. (1971). The study and improvement of sports technique. The doctrine of training. Moscow: Physical Education and Sport.

[28] Pidkassistyy, P. I. (1972). Independent activity of students: Didactic analysis of the process and structure of reproduction and creativity. Moscow: Pedagogy.

[29] Nikolaenko, V. V. (2015). Formation of sports skills of young football players. Science and sports: current trends. Kazan: Publishing House of the Volga GAFKSiT, 1 (6). 61-66.

[30] Poldrack, R. A., Sabb, F. W., Foerde, K., Tom, S. M., Asarnow, R. F., \& Bookheimer, S. Y. (2005). The neural correlates of motor skill automaticity. Journal of Neuroscience, 25, 5356-5364.

[31] Singh, H. (2018). Skill Acquisition. Online available from https://www.scienceforsport.com/skill-acquisition/\#toggleid-1 